\title{
Plasma carboxypeptidase B downregulates inflammatory responses in autoimmune arthritis
}

\author{
Jason J. Song, ${ }^{1,2}$ Inyong Hwang, ${ }^{1,2}$ Kyung H. Cho, ${ }^{2}$ Michael A. Garcia, ${ }^{1,2}$ Arthur J. Kim,1,2 \\ Tiffany H. Wang, ${ }^{1,2}$ Tamsin M. Lindstrom, ${ }^{1,2}$ Annette T. Lee,, ${ }^{3}$ Toshihiko Nishimura, ${ }^{4}$ Lei Zhao, ${ }^{5}$ \\ John Morser, ${ }^{5}$ Michael Nesheim, ${ }^{6}$ Stuart B. Goodman,, 7 David M. Lee, ${ }^{8}$ S. Louis Bridges Jr., ${ }^{9}$ \\ for the Consortium for the Longitudinal Evaluation of African Americans with Early Rheumatoid \\ Arthritis (CLEAR) Registry, Peter K. Gregersen, ${ }^{3}$ Lawrence L. Leung, ${ }^{2,5}$ and William H. Robinson',2 \\ 1Division of Immunology and Rheumatology, Stanford University School of Medicine, Stanford, California, USA. 2VA Palo Alto Health Care System, \\ Palo Alto, California, USA. ${ }^{3}$ Feinstein Institute for Medical Research, North Shore-Long Island Jewish Health System, Manhasset, New York, USA. \\ ${ }^{4}$ Division of Pulmonary and Critical Care Medicine and ${ }^{5}$ Division of Hematology, Department of Medicine, Stanford University School of Medicine, Stanford, \\ California, USA. ${ }^{6}$ Department of Biochemistry and Medicine, Queen's University, Kingston, Ontario, Canada. ${ }^{7}$ Department of Orthopedics, \\ Stanford University School of Medicine, Stanford, California, USA. ${ }^{8}$ Department of Medicine and Division of Rheumatology, Immunology, and Allergy, \\ Brigham and Women's Hospital, Harvard Medical School, Boston, Massachusetts, USA. 9Division of Clinical Immunology and Rheumatology, \\ University of Alabama at Birmingham, Birmingham, Alabama, USA
}

The immune and coagulation systems are both implicated in the pathogenesis of rheumatoid arthritis (RA). Plasma carboxypeptidase B (CPB), which is activated by the thrombin/thrombomodulin complex, plays a procoagulant role during fibrin clot formation. However, an antiinflammatory role for CPB is suggested by the recent observation that $\mathrm{CPB}$ can cleave proinflammatory mediators, such as $\mathrm{C5a}$, bradykinin, and osteopontin. Here, we show that $\mathrm{CPB}$ plays a central role in downregulating $\mathrm{C} 5 \mathrm{a}$-mediated inflammatory responses in autoimmune arthritis. CPB deficiency exacerbated inflammatory arthritis in a mouse model of RA, and cleavage of $\mathrm{C5}$ a by CPB suppressed the ability of C5a to recruit immune cells in vivo. In human patients with RA, genotyping of nonsynonymous SNPs in the CPB-encoding gene revealed that the allele encoding a CPB variant with longer half-life was associated with a lower risk of developing radiographically severe RA. Functionally, this CPB variant was more effective at abrogating the proinflammatory properties of $\mathrm{C} 5 \mathrm{a}$. Additionally, expression of both CPB and C5a in synovial fluid was higher in patients with RA than in those with osteoarthritis. These findings suggest that $\mathrm{CPB}$ plays a critical role in dampening local, $\mathrm{C5a}$-mediated inflammation and represents a molecular link between inflammation and coagulation in autoimmune arthritis.

\section{Introduction}

Rheumatoid arthritis (RA) is an inflammatory arthritis characterized by activation of both inflammatory and coagulation pathways (1). Fibrin deposition, the culmination of the coagulation cascade, is a hallmark of RA synovium $(2,3)$. Deposited fibrin can promote inflammatory responses (4), while citrulline-modified fibrin(ogen) is a prominent target of RA-specific autoantibodies (5). In animal models of arthritis, inhibition of thrombin or fibrin reduces the severity of arthritis $(4,6)$. Clinically, the incidence of coronary artery disease (CAD) is increased in the RA population, and antiinflammatory therapy reduces CAD-associated mortality in RA patients $(7,8)$. However, the molecular links between inflammation and coagulation have not been well characterized.

Thrombin-activatable plasma carboxypeptidase B (CPB, also known as activated thrombin-activatable fibrinolysis inhibitor [TAFIa] or carboxypeptidase $U$ ) is a component of the coagulation pathway that protects blood clots from fibrinolysis (9). It is produced mainly by the liver as a zymogen (proCPB) and is also detected in platelets (10). Activation of CPB occurs during thrombotic events (11), through the removal of a so-called activation

Authorship note: Michael Nesheim is deceased.

Conflict of interest: David M. Lee is currently employed by Novartis Pharma AG. Citation for this article: J Clin Invest. 2011;121(9):3517-3527. doi:10.1172/JCI46387. peptide in the $\mathrm{N}$ terminus of proCPB (9). Although thrombin and plasmin can activate proCPB in vitro by cleaving the activation peptide, the thrombin cofactor thrombomodulin (TM) accelerates the rate of $\mathrm{CPB}$ activation approximately 1,000-fold by forming a thrombin/TM complex, which is considered the physiological activator of proCPB (12).

By removing C-terminal lysine residues exposed on partially degraded fibrin, $\mathrm{CPB}$ decreases the binding of plasminogen and tissue plasminogen activator to fibrin, thereby suppressing the generation of the fibrinolytic enzyme plasmin (13). Recently, several proinflammatory mediators, such as $\mathrm{C} 5 \mathrm{a}$, osteopontin (OPN), and bradykinin, have been identified as substrates of CPB in vitro $(14,15)$. Therefore, by cleaving fibrin lysines and thereby maintaining fibrin clots, CPB may serve a procoagulant and proinflammatory function. Alternatively, by suppressing the activity of the proinflammatory mediators $\mathrm{C} 5 \mathrm{a}, \mathrm{OPN}$, and bradykinin, CPB may serve an antiinflammatory function. Illustrating this duality of function, CPB deficiency was protective in a model of glomerulonephritis (16), whereas it increased lethality in a model of hepatitis (17). CPB could therefore play several contrasting roles in autoimmune arthritis. To investigate the role of CPB in autoimmune arthritis, we analyzed biological samples derived from patients with RA, as well as mice deficient in CPB or in substrates of CPB. In addition, we performed genotyping to determine whether non- 

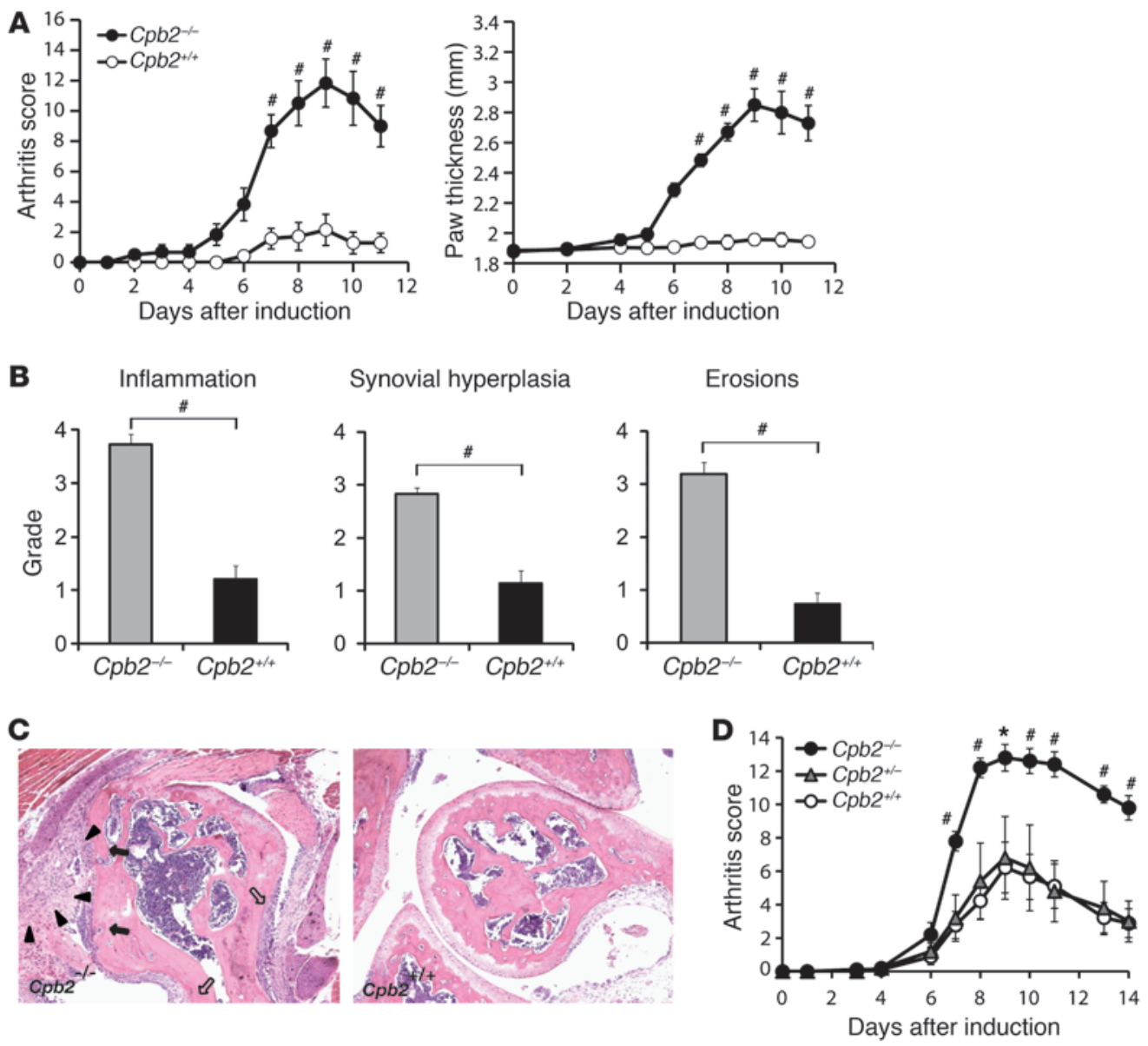

Figure 1

CPB protects against inflammatory arthritis in mice. CAIA was generated by i.v. injection of a suboptimal dose (2 mg) of anti-collagen antibodies on day 0, followed by i.p. injection of LPS on day 3. (A) CAIA severity and paw thickness in $\mathrm{Cpb2}^{-/-}$and $\mathrm{Cpb2} 2^{+/+}$mice. Compared with controls, $\mathrm{Cpb2}^{-/-}$mice exhibited significantly more severe arthritis from day 7 onward. (B) Histological scoring of arthritis severity based on degree of inflammation, synovial hyperplasia, and bone or cartilage erosions in the mice in A. (C) Representative H\&E-stained sections of joint tissue from mice in A (original magnification, $\times 200$ ). Arrowheads, inflammatory cell infiltrates; filled arrows, erosions of bone or cartilage; open arrows, synovial hyperplasia. (D) Gene-dose effect of $\mathrm{Cpb2}$ on CAIA. CAIA severity was measured in $\mathrm{Cpb2}^{+/+}, \mathrm{Cpb2}^{+/-}$, and $\mathrm{Cpb2}^{-/-}$mice. $1 \mathrm{copy}$ of Cpb2 provided the same level of protection against CAIA as did 2 copies. Results are representative of $2-3$ independent experiments $(n=5$ per group). ${ }^{\#} P<0.01,{ }^{*} P<0.05$ vs. control at each time point, Mann-Whitney $U$ test.

synonymous SNPs in CPB2 are associated with human RA. Our findings indicate that $\mathrm{CPB}$ plays a protective role in autoimmune arthritis by cleaving $\mathrm{C} 5 \mathrm{a}$ and thereby suppressing inflammatory cell migration and activation.

\section{Results}

$C P B$ protects against anti-collagen antibody-induced arthritis. To investigate the role of $\mathrm{CPB}$ in inflammatory arthritis, we generated anti-collagen antibody-induced arthritis (CAIA) in mice lacking Cpb2. At 7-10 days after injection with the anti-collagen antibodies, Cpb2 $2^{-/-}$mice exhibited more severe arthritis than $\mathrm{Cpb2}^{+/+}$mice (Figure 1A). Histologic analysis of joint sections revealed greater erosive damage, synovial hyperplasia, and inflammatory cell infiltration in $\mathrm{Cpb2^{-/- }}$ compared with $\mathrm{Cpb2^{+/+ }}$ mice (Figure 1, B and C). These findings demonstrate that $\mathrm{CPB}$ protects against the development of inflammatory arthritis. To assess the gene-dose effect

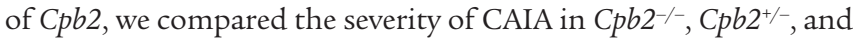

$C p b 2^{+/+}$mice and found that $C p b 2$ heterozygosity was sufficient to protect against the severe CAIA seen in Cpb2-/- mice (Figure 1D).

Deficiency in $C 5$, but not OPN or bradykinin receptor $B 2$, protects against CAIA. To determine which of CPB's substrates is involved in CAIA, we induced CAIA in C5-deficient mice, OPN-deficient (Spp1-/-) mice, and bradykinin $\mathrm{B} 2$ receptor-deficient (Bdkrb2-/-) mice. We chose $B d k r b 2^{-/-}$over $B d k r b 1^{-/-}$mice because the $\mathrm{B} 2$ receptor binds uncleaved bradykinin with greater affinity than CPB-cleaved bradykinin, whereas the $\mathrm{B} 1$ receptor preferentially binds CPB-cleaved bradykinin (18). In contrast to the experiments presented in Figure 1, in which a suboptimal dose of anti-collagen antibodies was used to induce arthritis, an optimal dose of anti-collagen antibodies was delivered for experiments involving CPB substrate-deficient mice. Compared with controls, C5-deficient mice were resistant to CAIA (Figure 2A), consistent with a previous report (19). In contrast, there was no difference in arthritis severity between $S p p 1^{-/-}$or $B d k r b 2^{-/-}$mice and their respective controls (Figure 2A). 

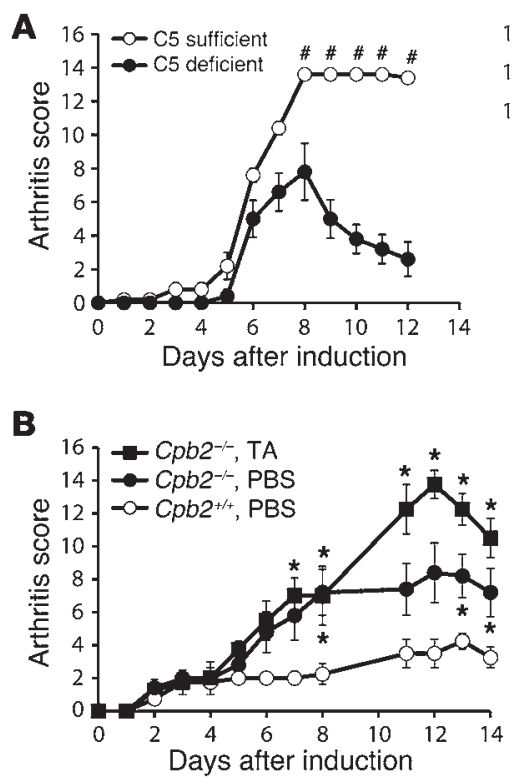

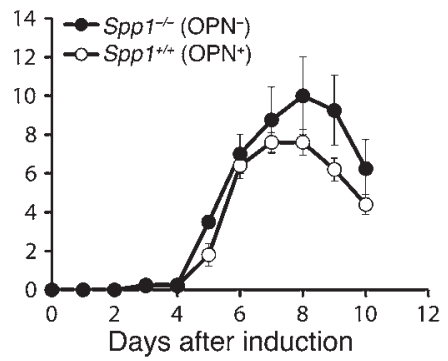

C

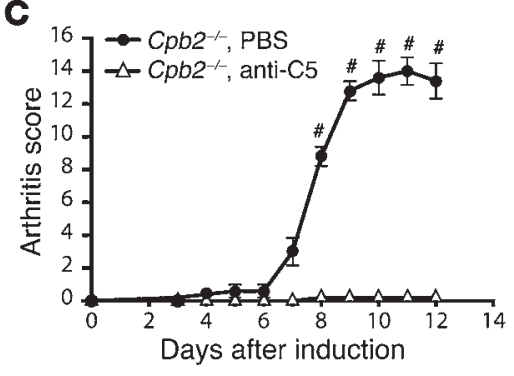

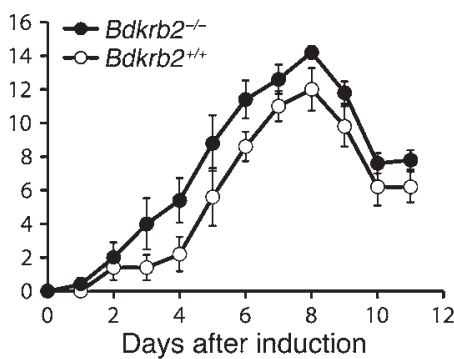

D

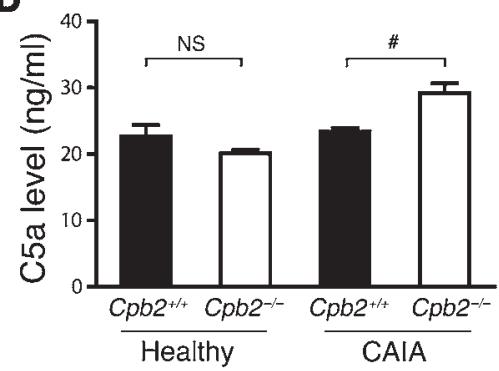

\section{Figure 2}

Role of CPB substrates in CAIA. (A) CAIA severity in C5-deficient, Spp1-/-, and Bdkrb2-/- mice and their respective controls. Mice deficient in CPB substrates and their controls were injected with an optimal dose (4-6 mg) of anti-collagen antibodies. C5 deficiency conferred protection against CAIA. (B and C) CAIA severity in $\mathrm{Cpb2}^{-/-}$and $\mathrm{Cpb2}^{+/+}$mice treated with TA or anti-C5 antibody. (B) TA treatment did not reverse, but instead accentuated, the exacerbation of CAIA in $\mathrm{Cpb}^{-1-}$ mice. (C) Anti-C5 antibody prevented development of severe arthritis in $\mathrm{Cpb2} 2^{-/-}$mice. (D) $\mathrm{Cpb2}^{-/-}$and $\mathrm{Cpb2}^{+/+}$mice were injected with a suboptimal dose $(2 \mathrm{mg})$ of anti-collagen antibodies. Plasma C5a level increased after injection in $\mathrm{Cpb2}^{-/-}$compared with $\mathrm{Cpb2} 2^{+/+}$mice. Results are representative of $2-3$ independent experiments $\left(n=4-5\right.$ per group). ${ }^{*} P<0.01,{ }^{*} P<0.05$ vs. control at each time point, Mann-Whitney $U$ test.

Inhibition of plasmin with tranexamic acid aggravates CAIA in CPB-deficient mice. By cleaving the $\mathrm{C}$-terminal lysine residues exposed on partially degraded fibrin, $\mathrm{CPB}$ decreases the binding of plasminogen to fibrin, thereby suppressing the generation of plasmin (13). Thus, plasmin generation in response to fibrin deposition is heightened

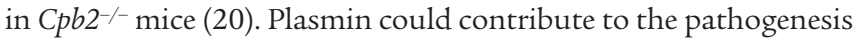
of arthritis by promoting cartilage degradation, either by directly cleaving cartilage proteoglycans or by activating MMPs (21). To determine whether an increase in plasmin levels accounts for the exacerbation of arthritis in Cpb2 $2^{-/-}$mice, we induced CAIA in Cpb2-/mice and treated them with tranexamic acid (TA), which blocks plasmin generation. TA treatment did not reverse, but instead accentuated, the exacerbation of CAIA in Cpb2 $2^{-1-}$ mice (Figure $2 \mathrm{~B})$. These findings suggest that the increase in arthritis severity in $C p b 2^{-/-}$mice is not mediated by plasmin and are consistent with a previous report in which inhibition of plasmin increased fibrin accumulation in the synovium and exacerbated arthritis (22). These observations may reflect fibrin's proinflammatory properties.

Anti-C5 antibody prevents development of severe arthritis in CPB-deficient mice. The anti-C5 antibody BB5.1 inhibits the cleavage of $\mathrm{C} 5$ into C5a and C5b (23). We treated CAIA in Cpb2 $2^{-/-}$mice with anti-C5 antibody. Anti-C5 antibody prevented the development of severe arthritis in Cpb2-/- mice (Figure 2C), which suggests that

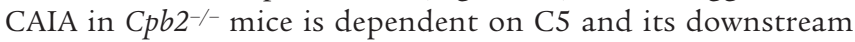
effector molecules. We also measured levels of C5a in plasma from


$\mathrm{Cpb2} 2^{-/-}$compared with $\mathrm{Cpb2^{+/+ }}$ mice with CAIA (Figure 2D), which confirms that $\mathrm{CPB}$ downregulates inflammatory responses by C5a cleavage. The protective effect of anti-C5 antibody on CAIA

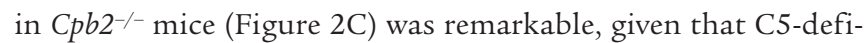
cient mice developed mild CAIA (Figure 2A). The influence of mouse genetic background on CAIA severity is well established (24), and the C5-deficient mice used in these experiments were of a mixed genetic background derived from C57BL/10 and DBA/2 (25), whereas the $\mathrm{Cpb2^{-/- }}$ mice were on the C57BL/6 background (26). Furthermore, the C5-deficient mice received $4 \mathrm{mg}$ of anti-collagen antibodies, whereas the $C p b 2^{-/-}$mice received only $2 \mathrm{mg}$ of anti-collagen antibodies. It is possible that differences in genetic background, the lower dose of anti-collagen antibodies, and/or possible off-target effects of the anti-C5 antibody BB5.1 could be responsible for the great extent to which arthritis severity was reduced in $C p b 2^{-1-}$ mice treated with BB5.1 (Figure 2C).

$C P B$ regulates inflammatory cell migration by cleaving $C 5 a$. To further explore the interaction between CPB and C5a, we examined the effect of CPB-mediated cleavage on the chemotactic properties of $\mathrm{C} 5 \mathrm{a}$ in vivo. Because it is difficult to obtain sufficient mouse synovial fluid for cellular analyses, we initially assessed C5a's ability to recruit inflammatory cells to the mouse peritoneal cavity. We incubated recombinant $\mathrm{C} 5 \mathrm{a}$ with $\mathrm{CPB}$ in order to generate the $\mathrm{CPB}$ cleaved form of $\mathrm{C} 5 \mathrm{a}$ (C5a-desArg; lacking the $\mathrm{C}$-terminal arginine) and confirmed removal of the $\mathrm{C}$-terminal arginine by mass spectrometry (Figure 3A). We then injected C5a that had been treated with either $\mathrm{CPB}$ or PBS into the peritoneal cavity of wild-type mice, and 5 hours later harvested peritoneal fluid for flow cytometric analysis. There were fewer neutrophils in peritoneal fluid from mice administered CPB-treated C5a than from those administered PBS-treated C5a (Figure 3B). CPB-treated C5a also induced less synovial inflammation than did PBS-treated C5a when injected 

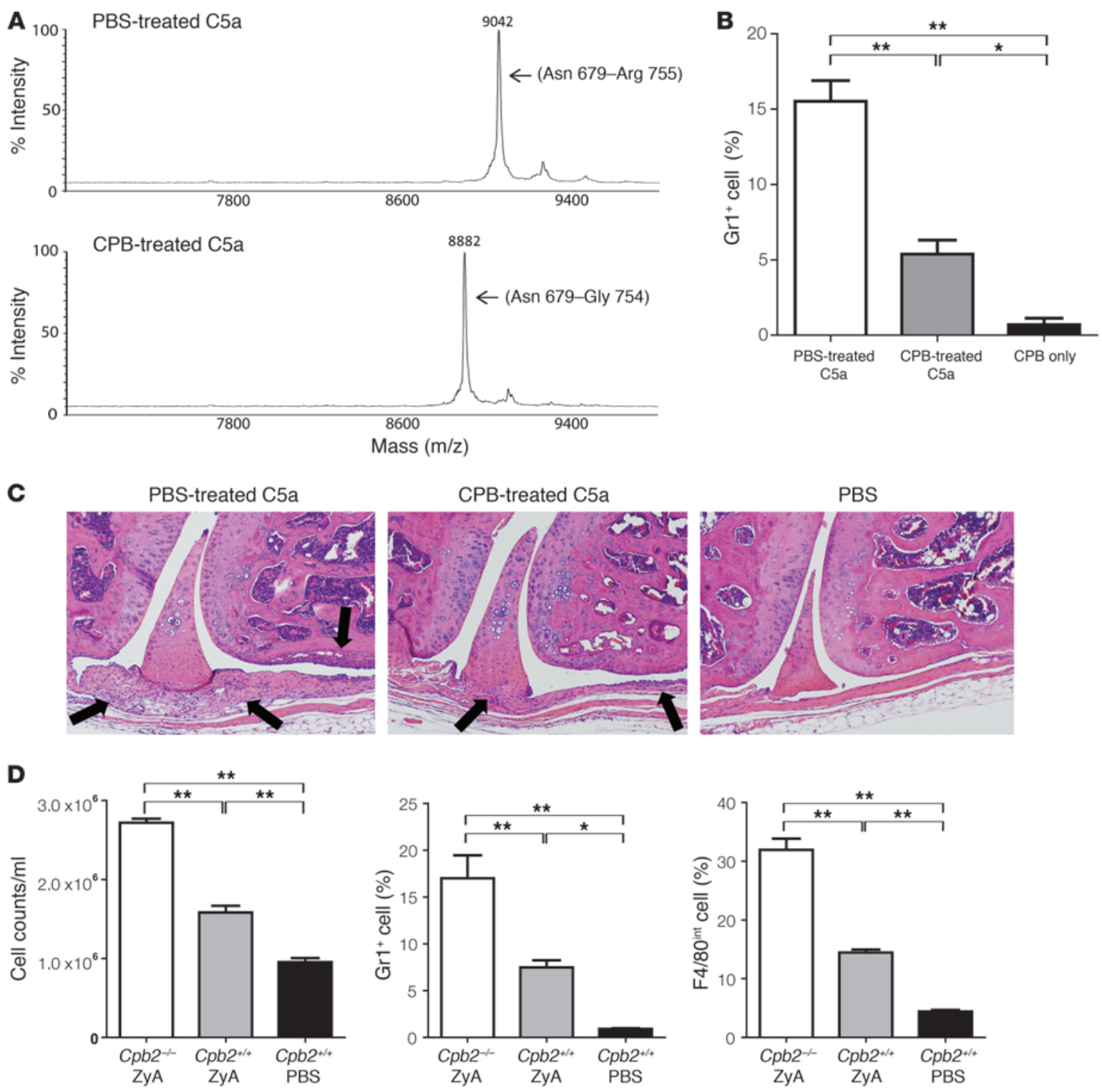

Figure 3

CPB cleavage of C5a suppresses neutrophil and macrophage chemotaxis to the peritoneum and synovium. (A) MALDI-TOF analysis of C5a incubated with PBS or CPB, showing the loss of arginine from CPB-treated C5a. (B) Flow cytometric analysis of peritoneal fluid cells from wildtype mice injected i.p. with CPB-treated or PBS-treated C5a or with CPB alone. Antibodies against Gr1 were used to identify neutrophils. (C) H\&E-stained sections of mouse stifle joints injected with CPB- or PBS-treated C5a or with PBS alone (original magnification, $\times 400$ ). Arrows show inflammatory cell infiltrates in synovial tissues; there was less accumulation of immune cells in response to CPB-cleaved C5a than PBStreated C5a. (D) Flow cytometric analysis of peritoneal fluid cells from $\mathrm{Cpb}^{-/-}$and $\mathrm{Cpb2} 2^{+/+}$mice injected i.p. with ZyA. Antibodies against F4/80 (macrophage marker) and Gr1 (neutrophil marker) were used. Results are representative of 2 independent experiments $(n=5$ per group). ${ }^{* *} P<0.01,{ }^{*} P<0.05,1$-way ANOVA and Tukey test.

into the stifle (knee) joints of mice (Figure 3C). Furthermore, using the Zymosan A-induced (ZyA-induced) peritonitis model, in which inflammatory cells are recruited to the peritoneum in a C5a-dependent manner (27), we found that neutrophil and macrophage recruitment was greater in $\mathrm{Cpb2}^{-/-}$than in $\mathrm{Cpb}^{+/+}$mice (Figure 3D). These data suggest that CPB is antiinflammatory by cleaving C5a, thus inactivating C5a's chemotactic properties.

CPB SNP 1040 T encoding the long half-life Ile325 CPB protects against radiographic progression of $R A$. We next performed genotyping to determine whether polymorphisms in the $C P B 2$ gene are associated with human RA. Previously, 2 nonsynonymous SNPs have been reported in the coding region of CPB2: rs3742264 (G505A encoding Ala147Thr) and rs1926447 (C1040T encoding Thr325Ile) (28, 29). Only the C1040T SNP has known functional consequences, with Ile325 CPB having a 2-fold longer half-life and being more effective at inhibiting fibrinolysis than Thr325 CPB (30). We genotyped the 2 nonsynonymous CPB2 SNPs in an African American RA cohort (the Consortium for the Longitudinal Evaluations of 
Table 1

Nonsynonymous CPB2 SNP case-control analysis

\begin{tabular}{lcc}
\hline & $\begin{array}{c}\text { rs1926447 } \\
\text { (C1040T) }\end{array}$ & $\begin{array}{c}\text { rs3742264 } \\
\text { (G505A) } \\
\text { Sample size, cases/controls }\end{array}$ \\
$\begin{array}{l}\text { (G71/805 } \\
\text { Genotype, cases }\end{array}$ & $778 / 803$ \\
AA & 598 & 271 \\
AB & 157 & 391 \\
BB & 16 & 116 \\
Genotype, controls & & \\
AA & 599 & 301 \\
AB & 186 & 380 \\
BB & 20 & 122 \\
Minor allele frequency & & \\
Cases & 0.12 & 0.40 \\
Controls & 0.14 & 0.39 \\
Allelic $\chi^{2} P$ & 0.14 & 0.50 \\
Genotype association, AA vs. AB+BB & & \\
Odds ratio & 0.84 & 1.12 \\
95\% confidence interval & $0.67-1.06$ & $0.91-1.38$ \\
$\chi^{2}$ & 2.14 & 1.20 \\
$P$ & 0.14 & 0.27 \\
\hline
\end{tabular}

Sample size refers to the number of samples successfully genotyped. A and B denote the major (for rs1926447, C; for rs3742264, G) and minor (for rs 1926447, T; for rs3742264, A) alleles, respectively, for each SNP.

African Americans with Early Rheumatoid Arthritis [CLEAR] Registry) and in age- and gender-matched healthy individuals. Using our genotyping data, we first asked whether the C1040T SNP (rs1926447) is associated with susceptibility to RA; we found no significant association (Table 1). We next asked whether the C1040T SNP is associated with RA severity, as assessed by radiography of hands and feet and quantified by the modified Sharp/van der Heijde score (SHS) (31). For this analysis, we used data from the subset of CLEAR I RA patients for which the 3-year follow-up SHS were available $(n=118)$ and divided the patients into those with severe radiographic RA (defined as the top tertile of SHS) and those with mild RA (middle and bottom tertiles) (32). We then determined how many of the patients with radiographically severe RA were homozygous (CC) for the $1040 \mathrm{C}$ allele (encoding short half-life Thr325 CPB) and how many were carriers (CT or TT) of the $1040 \mathrm{~T}$ allele (encoding long half-life Ile325 CPB). Compared with $1040 \mathrm{C}$ homozygotes, carriers of the $1040 \mathrm{~T}$ allele had a relative risk reduction of $70 \%$ for developing radiographically severe RA within 3 years $\left(P=0.026, \chi^{2}\right.$ test; Figure 4 and Table 2$)$. There were no significant differences in age, disease duration, disease activity score based on 28 joints (DAS28), or other nonradiographic markers of disease activity between $1040 \mathrm{C}$ homozygotes and $1040 \mathrm{~T}$ carriers (Table 3). G505A (rs3742264), the nonsynonymous CPB2 SNP that has no known functional consequence, was not associated with radiographic severity (Figure 4).

Ile325 CPB is more effective than Thr325 CPB at neutralizing C5a. To gain insight into the mechanism underlying the genotype association, we compared the ability of the $\mathrm{CPB}$ variants encoded by the C1040T SNP to inactivate C5a. We incubated C5a with Thr325 CPB (encoded by 1040C) or Ile325 CPB (encoded by 1040T) and used mass spectrometry to measure the generation of C5a-desArg. By evaluating the ratio of C5a-desArg to intact C5a, we found that the long half-life Ile325 CPB cleaved C5a to a greater extent than did the short half-life Thr325 CPB (Figure 5A). Furthermore, after 1 hour, C5a treated with Ile 325 CPB retained only $21 \%$ of its activity, as assessed by its ability to induce neutrophil myeloperoxidase (MPO) release, whereas C5a treated with Thr325 CPB retained as much as $69 \%$ of its activity (Figure 5B). Thus, the long half-life Ile325 CPB is 3 times as effective as the short half-life Thr325 CPB at neutralizing the proinflammatory mediator $\mathrm{C} 5 \mathrm{a}$, a difference that may provide the molecular basis for the protective effect of the CPB2 1040T allele on radiographic severity in RA.

$C P B$ levels are elevated in RA synovial fluid and correlate with C5a levels. We next measured C5a and CPB protein levels in synovial fluid and plasma from RA patients. Total CPB levels were higher in RA compared with osteoarthritis (OA) synovial fluid samples (Figure $6 \mathrm{~B})$, consistent with a previous report (33). Total C5a levels were also higher in RA compared with OA synovial fluid samples, and synovial fluid CPB levels correlated with C5a levels (Figure 6B). Our data, demonstrating an antiinflammatory role for CPB in murine inflammatory arthritis, suggest that the increase in $\mathrm{CPB}$ expression in RA occurs as part of an antiinflammatory feedback mechanism. Data regarding the levels of CPB in the plasma of RA patients are conflicting $(34,35)$. Although CPB is produced mainly by the liver, we did not observe any differences in plasma CPB levels between RA patients and healthy individuals (Figure 6A), which suggests that the increase in CPB levels in synovial fluid in RA is caused by local production of CPB.

$C P B$ is locally expressed in $R A$ joints. Immunohistochemical analysis showed that CPB protein was present in RA synovial tissues in an interstitial pattern as well as an intracellular pattern (Figure 7). To determine whether CPB is produced locally in the synovial joints in RA, we examined CPB2 mRNA expression in synovial tissue and cells from synovial fluid. Although we recently showed that cultured fibroblast-like synoviocytes (FLSs) can produce CPB (15), assessment of CPB2 expression in situ revealed CPB2 mRNA expression in cells from RA synovial fluid and in RA synovial tissues (Figure 8A). Because inflammatory cells in synovial fluid derive from blood, we assessed CPB2 expression in cells obtained from peripheral blood. Peripheral blood cells and macrophages
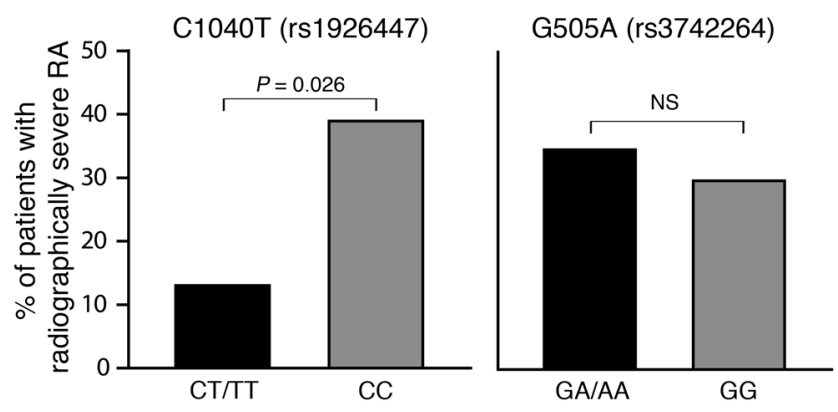

\section{Figure 4}

RA patients who possess the CPB2 1040T allele, encoding long half-life $\mathrm{CPB}$, have a lower risk of progressing to radiographically severe RA. RA patients in the CLEAR I cohort $(n=118)$ who developed radiographically severe RA (defined as the top tertile of radiographic severity, based on SHS) were stratified by the nonsynonymous CPB2 SNPs rs 1926447 (C1040T) and rs3742264 (G505A). Compared with 1040C homozygotes, fewer carriers of 1040T, which encodes lle325 CPB, developed radiographically severe RA within 3 years (1040C homozygotes, $39 \%$; 1040 T carriers, $13 \% ; P=0.026, \chi^{2}$ test). In contrast, the G505A (rs3742264) genotype was not associated with radiographic severity. 
Table 2

CPB2 SNP rs1926447 (C1040T) genotype frequency in RA, stratified by radiographic severity

\begin{tabular}{lccccc} 
& CT/TT, $\boldsymbol{n}(\%)$ & CC, $\boldsymbol{n}(\%)$ & Odds ratio (95\% CI) & Relative risk (95\% CI) & $\boldsymbol{P}$ \\
Severe & $3(13.0)$ & $37(38.9)$ & $0.24(0.07-0.85)$ & $29.3 \%(9.2-92.6)$ & 0.026 \\
Mild & $20(87.0)$ & $58(61.1)$ & & & \\
\hline
\end{tabular}

Severe and mild were defined as the top tertile and the middle and bottom tertile, respectively, of radiographic severity as measured by modified SHS. processes that are tightly regulated in the RA joint.

Although CPB markedly inhibits fibrinolysis in vitro, CPB-deficient mice have no overt phenotype or coagulation abnormalities (20). Moreover, restoration of antifibrinolytic activity by TA in CPB-deficient mice exacerbated inflammatory arthritis, which suggests that inhibition of fibrinolysis is not the main mechanism by which CPB protects differentiated in vitro expressed CPB (Figure 8B). The macrophage differentiation factor M-CSF, which is highly expressed in RA synovial fluids (36), increased CPB2 expression in the monocyte cell line U937 (Figure 8C). In addition, dexamethasone, a potent antiinflammatory agent, increased $C P B 2 \mathrm{mRNA}$ and $\mathrm{CPB}$ protein expression in U937 cells (Figure 8, C and D). Thus, local production by synovial inflammatory cells and synoviocytes may account for the increase in CPB levels in RA joints.

\section{Discussion}

Several components of the coagulation pathway are involved in inflammation (37). For example, the procoagulant fibrin is proinflammatory by promoting the migration and activation of inflammatory cells and the production of proinflammatory cytokines (38), whereas the anticoagulant protein $\mathrm{C}$ is antiinflammatory by promoting the cytoprotective pathways that inhibit apoptosis or cytokine productions (39). CPB possesses both antifibrinolytic activity (and thus potentially proinflammatory activity) and antiinflammatory activity, and its role in inflammatory arthritis has not been characterized. In this study, we demonstrated that CPB protected against inflammatory arthritis in mice, exerting an antiinflammatory effect by inactivating the anaphylatoxin $\mathrm{C} 5 \mathrm{a}$. Our results with TA suggest that this effect is not mediated by the fibrin-plasmin pathway. Our findings in mice translated to human RA, in which carriage of the CPB2 1040T allele (encoding the long half-life Ile325 $\mathrm{CPB}$ ) protected against erosive damage of RA joints. Furthermore, we found that the long half-life Ile325 CPB neutralized C5a activity more effectively than its short half-life counterpart, a difference that may underlie the protection conferred by the CPB2 1040T allele. Together, our findings suggest that $\mathrm{CPB}$ is a molecular link between inflammation and coagulation in RA. Activated during coagulation, $\mathrm{CPB}$ dampens inflammation in the synovial joints and ultimately reduces joint damage in RA.

The RA joint provides an environment suitable for activation of CPB. In RA synovial fluid, molecular markers of thrombin activation (thrombin-anti-thrombin III complexes and thrombin fragments) are significantly elevated (33). In addition, TM levels are increased in RA synovial fluids, and TM is expressed in RA joint tissue, mainly in endothelial cells and synovial lining cells (40). By forming the thrombin/TM complex, TM dramatically increases the rate of activation of both protein $\mathrm{C}$ and $\mathrm{CPB}$ approximately 1,000 -fold $(12,41)$. Although the 2 proteins activated by the thrombin-TM complex are both antiinflammatory, they have opposing effects on coagulation: whereas protein $C$ has anticoagulant activity, CPB has antifibrinolytic activity. Thus, coagulation and inflammation are interlinked against inflammatory arthritis. Indeed, our mouse data suggest that CPB's primary role in inflammatory arthritis is an antiinflammatory one. Among CPB's known proinflammatory substrates, OPN and bradykinin were not important in CAIA. C5a, in contrast, is known to be involved in autoimmune arthritis in humans and mice $(42,43)$. By cleaving C5a, CPB suppressed immune cell migration, a process important in RA pathogenesis.

Unlike in mice, there is no known case of CPB deficiency in humans. However, our human genomic data are consistent with our mouse phenotypic data showing that $C p b 2$ provides a protective effect on inflammatory arthritis. RA patients carrying the CPB2 allele encoding long half-life CPB (1040T) were less likely to progress to radiographically severe arthritis. We found that 1 copy of the allele was sufficient to provide protection, consistent with our results from mice heterozygously deficient in CPB. Interestingly, the CPB2 genotype was not associated with disease susceptibility, which suggests that the genetic factors that drive development of RA are distinct from those that drive progression of RA. CPB2 genotyping could potentially be performed in order to screen
Table 3

Clinical, laboratory, and radiologic characteristics of patients in the CLEAR I cohort, stratified by CPB2 SNP rs1926447 (C1040T)

\begin{tabular}{lccr}
\hline & CT/TT & CC & $P$ \\
$n$ & 23 & 95 & \\
Age (years) & $55.4 \pm 10.6$ & $59.8 \pm 13.6$ & 0.095 \\
Disease duration (months) & $103.4 \pm 12.8$ & $98.8 \pm 16.4$ & 0.148 \\
Smoking & $10(43.5)$ & $54(56.8)$ & 0.263 \\
Anti-CCP positive & $15(65.2)$ & $62(65.3)$ & 0.798 \\
RF positive & $19(82.6)$ & $69(72.6)$ & 0.721 \\
HLA-DRB1 shared epitope present & $11(47.8)$ & $46(48.4)$ & 0.960 \\
CRP, year 0 (mg/l) & $9.9 \pm 22.5$ & $15.2 \pm 33.4$ & 0.374 \\
Tender joint count (0-38) & $7.2 \pm 7.3$ & $8.7 \pm 8.9$ & 0.409 \\
Swollen joint count (0-42) & $4.9 \pm 6.2$ & $4.8 \pm 6.4$ & 0.968 \\
DAS28, year 0 & $3.7 \pm 1.4$ & $4.0 \pm 1.4$ & 0.371 \\
HAQ, year 0 & $1.7 \pm 0.9$ & $1.8 \pm 0.9$ & 0.942 \\
Treatment with DMARDs & $21(91.3)$ & $80(84.2)$ & 0.323 \\
SHS, year 0 & $0.3 \pm 0.8$ & $2.3 \pm 5.3$ & 0.001 \\
SHS, year 3 & $1.8 \pm 3.9$ & $5.9 \pm 12.0$ & 0.007 \\
Erosion score, year 0 & $0.3 \pm 0.8$ & $1.0 \pm 2.4$ & 0.035 \\
Erosion score, year 3 & $0.6 \pm 1.1$ & $2.6 \pm 6.5$ & 0.005 \\
JSN score, year 0 & $0.0 \pm 0.0$ & $1.3 \pm 3.5$ & $<0.001$ \\
JSN score, year 3 & $1.2 \pm 3.2$ & $3.2 \pm 6.3$ & 0.033 \\
\end{tabular}

Values are mean \pm SD or $n(\%)$, as applicable. $100 \%$ of patients were female. $\mathrm{CCP}$, cyclic citrullinated peptide antibody; RF, rheumatoid factor; DMARD, disease-modifying antirheumatic drug; JSN, joint-space narrowing; HAQ, health assessment questionnaire; CRP, C-reactive protein. HLA-DRB1 shared epitope alleles were *0101, *0102, *0401, *0404, "0405, *0413, *1001, and *1402. 

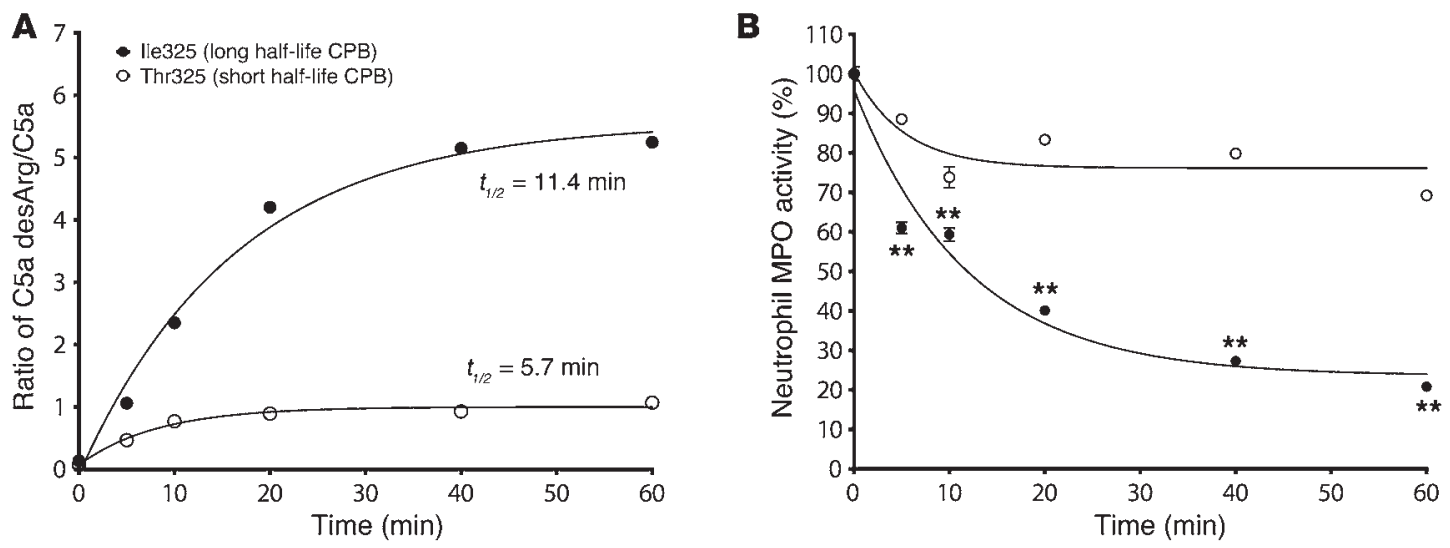

\section{Figure 5}

C5a-neutralizing activities of CPB variants. (A) C5a-desArg generation by CPB variants. The ratio of C5a-desArg to intact C5a at each time point was measured by mass spectrometry, the data fit was calculated by 1 -phase exponential models, and half-times $\left(t_{1 / 2} ; 50 \%\right.$ of the time necessary to reach the calculated plateau) of C5a cleavage was determined. The lle325 CPB variant's half-time was twice as long as that of Thr325 CPB. (B) C5a neutralization by CPB variants. Ile325 CPB was more efficient than Thr325 CPB at neutralizing C5a activity, as assessed by C5a-mediated induction of neutrophil MPO release. Activity of C5a over time is presented as a percentage of C5a activity at 0 minutes of CPB treatment. ${ }^{\star \star} P<0.01$, Student's $t$ test.

for RA patients who are at risk of progressing to a severe, erosive form of the disease or to predict the response of RA patients to therapeutic inhibitors targeting CPB substrates, such as anti-C5a therapy. Even though the CPB2 1040 T allele had a protective effect on RA, it is also associated with an increased risk of certain thrombotic diseases (44-47), which demonstrates the diverse role of CPB in inflammation and coagulation.

Although erosive changes were reduced in patients carrying the CPB2 1040T allele, we observed no differences in other disease activity indices, including DAS28, health assessment questionnaire score, tender joint count, and CRP, between CPB2 1040T allele carriers and $1040 \mathrm{C}$ homozygotes. CPB may have a direct role in bone and/or cartilage erosion in addition to its role in inflammation, given that there is evidence that $\mathrm{C} 5$ a plays a direct role in bone and cartilage erosion by mediating osteoclast activation (48) and by inducing MMP expression by RA FLSs (Supplemental Figure 1, $A$ and $B$; supplemental material available online with this article; doi:10.1172/JCI46387DS1). Alternatively, the differences in CPB half-life may not be sufficient to affect inflammatory markers at a single time point, but could potentially dampen chronic inflammatory responses over time and thereby reduce erosive progression.
Multiple genetic factors associated with RA have been discovered during the last decade (49). Understanding their contribution to RA pathogenesis requires evaluation of their biological effects. However, for the vast majority of genetic variants associated with $\mathrm{RA}$, there is no known functional effect of the variants. Here we demonstrated that long half-life CPB had greater C5a-neutralizing capability. Nevertheless, the molecular mechanisms by which the genetic variants of CPB affect RA may extend beyond regulation of inflammation mediated by $\mathrm{C} 5 \mathrm{a}$, because $\mathrm{C} 5$ inhibition using a neutralizing antibody provided only a trend toward modest benefit in human RA (50), and C5a-receptor inhibition failed to provide benefit (51). Thus, it remains possible that CPB's effect in RA is mediated through multiple substrates.

Once activated, $\mathrm{CPB}$ has a short half-life of $5-10$ minutes at $37^{\circ} \mathrm{C}$ (52). No physiological inhibitors of CPB have been identified, and inactivation of CPB is achieved only through spontaneous structural destabilization of CPB after release of its activation peptide (53). Therefore, the stability of CPB is an important determinant of its functional activity. In addition, CPB levels are higher in RA synovial fluids than in OA synovial fluids, possibly secondary to chronic inflammation and activation of the coagulation pathway
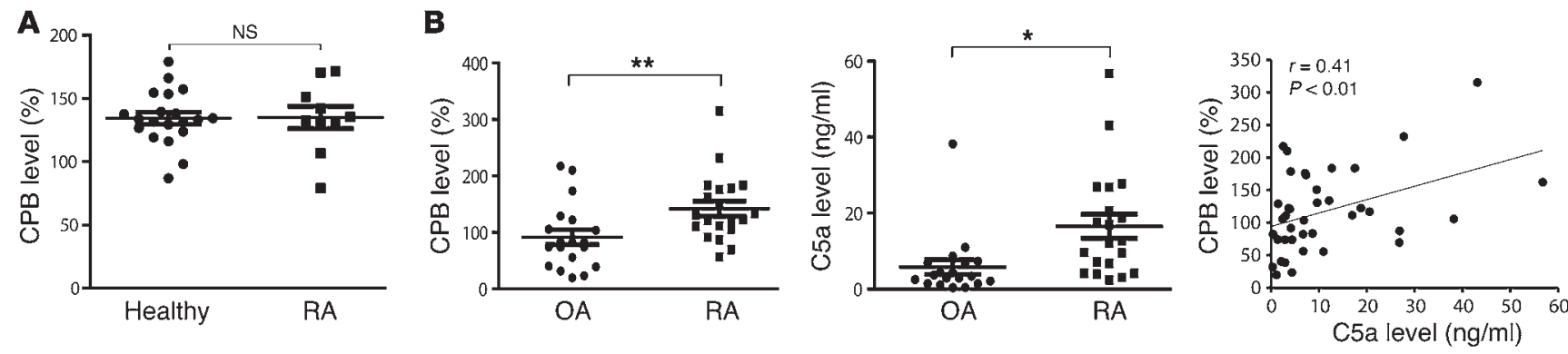

Figure 6

CPB levels in plasma and synovial fluid of RA patients. (A) Similar levels of CPB were present in plasma derived from RA patients $(n=10)$ and healthy controls $(n=20)$. (B) CPB and total C5a levels were elevated in RA $(n=20)$ compared with OA $(n=19)$ synovial fluid $\left({ }^{*} P<0.05\right.$, ${ }^{\star \star} P<0.01$, Student's $t$ test). CPB levels correlated with total C5a levels $(P<0.01$, Pearson correlation test) in RA and OA synovial fluid. 

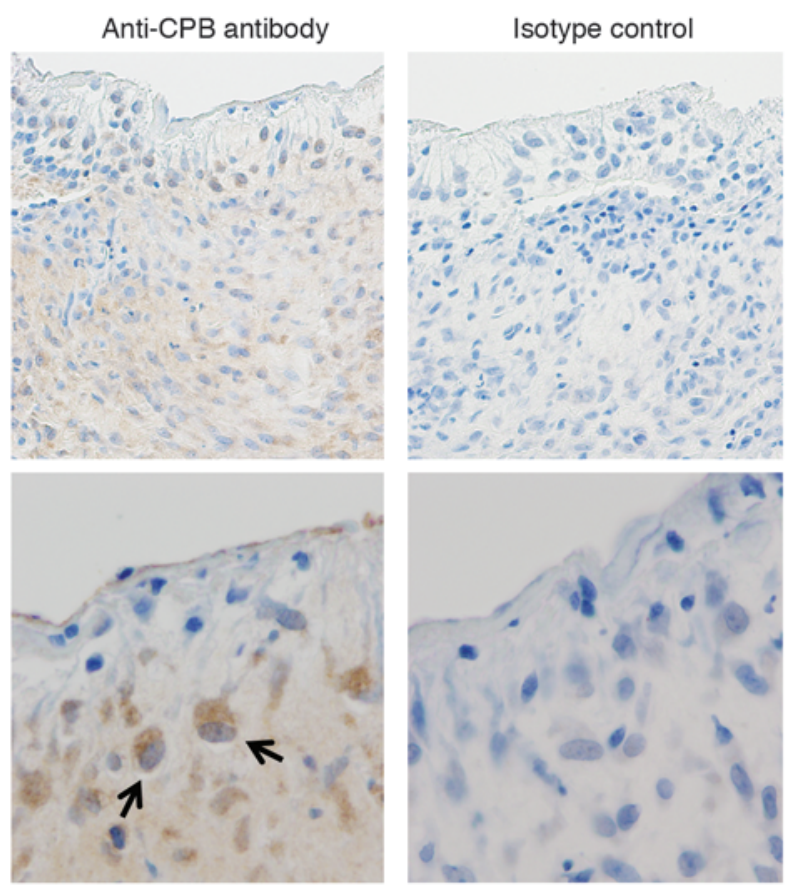

\section{Figure 7}

Immunohistochemical detection of CPB in RA synovium. Sections of paraffin-embedded RA synovium were stained with a rabbit polyclonal anti-CPB antibody. Brown color indicates positive staining. Rabbit IgG was used as a negative isotype control. CPB was predominantly detected in an interstitial distribution, but there were also cells that exhibited a cytoplasmic staining pattern (arrows) suggestive of local production of CPB in RA synovium. Original magnification, $\times 200$ (top), $\times 1,000$ (bottom).

ing paw thickness. For the TA studies, mice received $15 \mathrm{mg}$ TA (Pfizer) via subcutaneous injection 1 day before the injection of anti-collagen antibody, and then daily until the conclusion of the study, using previously described protocols (54). Mice were also injected with $40 \mu \mathrm{g}$ LPS on days 3 and 8 . For the anti-C5 antibody studies, mice received $750 \mu \mathrm{g}$ anti-C5 antibody i.p. (provided by V.M. Holers, University of Colorado, Denver, Colorado, USA) on days 0 and 2 using previously described protocols (23).

Scoring of murine arthritis. Arthritis in mice was scored according to the following visual scoring system, as previously described (55): 0 , no swelling or erythema; 1 , mild swelling and erythema or digit inflammation; 2 , moderate swelling and erythema confined to the region distal to the mid-paw; 3 , pronounced swelling and erythema with extension to the ankle; 4 , severe swelling, erythema, and joint rigidity of the ankle, foot, and digits. Each limb was graded with a score of $0-4$, with a maximum possible score of 16 for each individual mouse. Paw thickness was determined by measuring the thickness of the hind paws with $0-10 \mathrm{~mm}$ calipers.

Tissue processing. Joint tissue was harvested, decalcified, and embedded as part of a compensatory antiinflammatory mechanism. Therefore, it is highly plausible that differences in the half-life of distinct $\mathrm{CPB}$ variants could influence disease progression in $\mathrm{RA}$. CPB levels in plasma, however, did not differ between RA patients and healthy individuals, which suggests that CPB is produced locally in RA. We have previously demonstrated that cultured FLSs express CPB (15), and showed in the present study that immune cells also produced CPB. Local production of CPB might be important in modulating local inflammatory processes.

Together, our findings suggest that $\mathrm{CPB}$, a component of the coagulation system, plays a critical role in downregulating local inflammation in autoimmune arthritis. CPB exerted not only an antifibrinolytic effect, but also an antiinflammatory one. By cleaving $\mathrm{C} 5 \mathrm{a}, \mathrm{CPB}$ dampened inflammation in the synovial joints in a mouse model of autoimmune arthritis.

\section{Methods}

Mouse studies. Cpb2-/- mice were extensively backcrossed to the C57BL/6J background at the Jackson Laboratory as previously described (26), and $\mathrm{C} 57 \mathrm{BL} / 6 \mathrm{~J}$ mice or $\mathrm{Cpb2^{+/+ }}$ littermates were used as controls. C5-deficient mice, $S p p 1^{-/-}$mice, $B d k r b 2^{-/-}$mice, and controls were purchased from Jackson Laboratory. Mice were housed at Stanford University, and experiments were performed under protocols approved by the Stanford University Committee of Animal Research and in accordance with NIH guidelines. CAIA was induced by tail vein injection of anti-collagen II antibody (Arthrogen-CIA; Chondrex), followed by i.p. injection of $50 \mu \mathrm{g}$ LPS (Sigma-Aldrich) 3 days later. Mice deficient in CPB substrates and their controls were injected with an optimal dose (4-6 mg/mouse) of anti-collagen antibody to induce severe arthritis in the control groups, so that we could observe a reduction in severity caused by deficiency in a CPB substrate. In contrast, CPB-deficient mice and their controls were injected with a suboptimal dose $(2 \mathrm{mg} / \mathrm{mouse})$ of anti-collagen antibody to minimize arthritis in their control groups, so that we could observe an exacerbation of disease in CPB-deficient mice. Mice were scored daily for arthritis by using the visual scoring system and by measur$\mathrm{H} \& \mathrm{E}$ and scored by a blinded examiner for inflammatory cell infiltrates, erosion of cartilage or bone, and synovial hyperplasia.

ZyA-induced peritonitis model. Peritoneal inflammation was induced as previously described (56). ZyA (Sigma-Aldrich) was prepared in sterile PBS $(2 \mathrm{mg} / \mathrm{ml})$, and $0.5 \mathrm{ml}$ was i.p. injected into mice. At selected time points, animals were euthanized, and peritoneal cells were harvested by lavage with 5 mM EDTA-PBS. Cells were counted with a hemocytometer and stained for granulocytes and macrophages with anti-mouse Gr1 and F4/80 (BD Biosciences). Cells $\left(1 \times 10^{6}\right.$ per tube) were incubated with purified Fc block (anti-mouse CD16/CD32; BD Biosciences) for 5 minutes, washed, resuspended in staining buffer, and analyzed using a FACScaliber flow cytometer (BD Biosciences).

In vivo chemotaxis assay. $120 \mu \mathrm{M}$ C5a (R\&D Systems) was incubated with $70 \mathrm{nM}$ activated CPB (American Diagnostica) in HBSS for 45 minutes at room temperature and for 15 minutes at $37^{\circ} \mathrm{C}$. Analysis of full-length $\mathrm{C} 5 \mathrm{a}$ (Asn679-Arg755) and CPB-cleaved C5a (Asn679-Gly754) was performed on a PerSeptive Voyager-DE RP Biospectrometry MALDI-TOF mass spectrometer operating in linear mode using delayed extraction under standard conditions at the Stanford Protein and Nucleic Acid Facility. 2.5 $\mu \mathrm{g}$ CPB- or PBStreated $\mathrm{C} 5 \mathrm{a}$ was injected into the mouse peritoneum. 5 hours after injection of $\mathrm{C} 5 \mathrm{a}$, peritoneal cells were harvested and analyzed as described above.

Intra-articular injection of C 5 a. $5 \mu \mathrm{l} \mathrm{CPB-} \mathrm{or} \mathrm{PBS-treated} \mathrm{C} 5 \mathrm{a}(0.5 \mathrm{mg} / \mathrm{ml})$ was injected into the mouse stifle joint using a 29-gauge needle and microsyringe (Hamilton Co.). Stifle joints were harvested and processed for $\mathrm{H} \& \mathrm{E}$ staining 72 hours later.

CLEAR Registry. The CLEAR Registry enrolled self-declared African Americans who were diagnosed with RA. CLEAR I is a longitudinal cohort of early RA (disease duration less than 2 years from time of symptom onset), and CLEAR II is a cross-sectional cohort of RA of any duration (57). Genotyping for CPB2 SNPs rs1926447and rs3742264 was performed using a custom Infinium iSelect Genotyping Beadchip (Illumina) on DNA samples from the CLEAR I $(n=337)$ and CLEAR II $(n=446)$ registries and from 
A

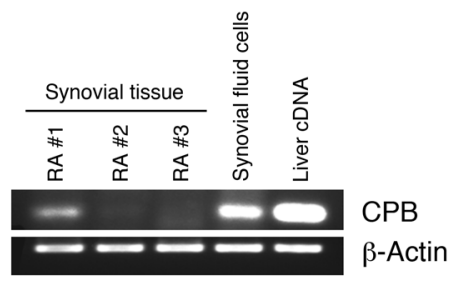

B

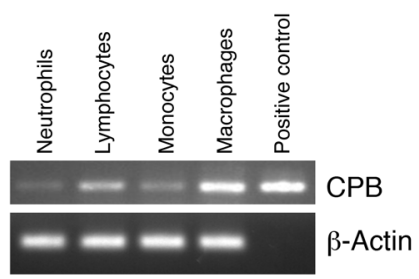

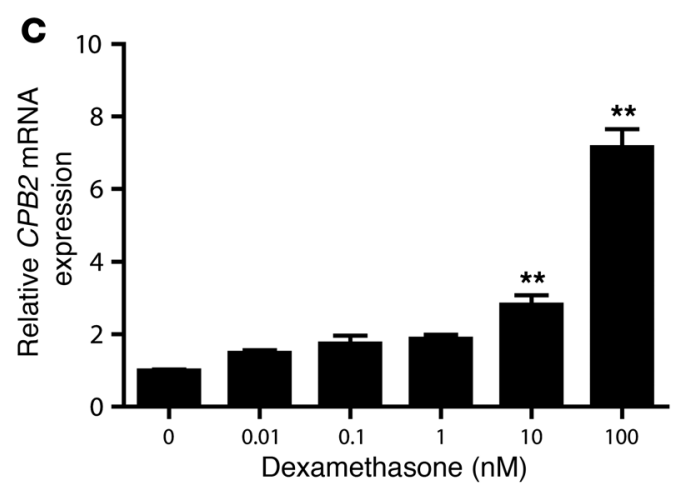
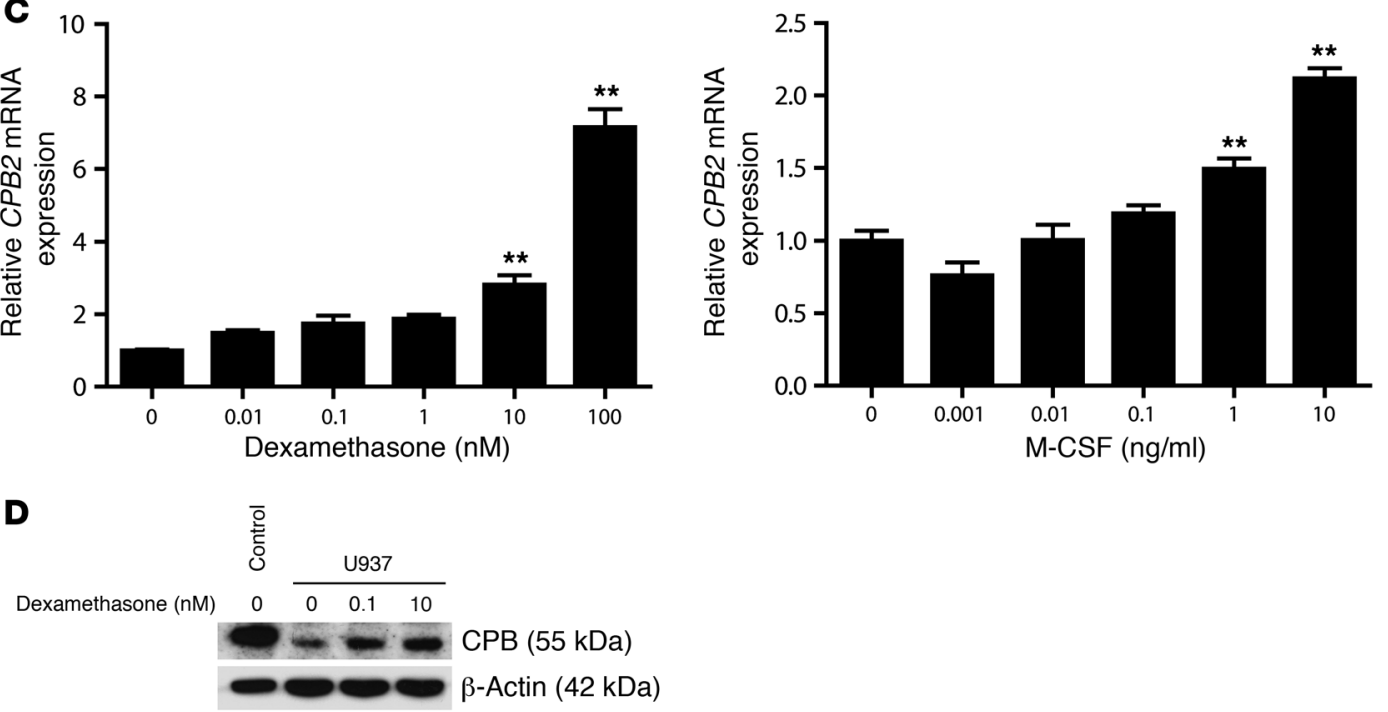

\section{Figure 8}

CPB expression in RA synovial tissue and inflammatory cells. (A) CPB2 mRNA expression in cells derived from RA synovial fluid and tissue. Liver cDNA was used as a positive control. (B) Expression of CPB2 mRNA in macrophages derived from a healthy donor. CPB2 cDNA was used as a positive control. (C) CPB2 mRNA expression in the promonocytic cell line U937 increased after treatment with dexamethasone or M-CSF. (D) Immunoblot analysis of proCPB expression in U937 cells showed dose-dependent induction of CPB expression by dexamethasone. Control cell lysates were from the Huh-7.5 hepatocyte cell line. Results (mean \pm SEM of triplicates) are representative of 2 independent experiments. ${ }^{\star \star} P<0.01,1$-way ANOVA and Dunnett test.

control healthy individuals $(n=808)$, as part of the International MHC and Autoimmunity Genetics Network (IMAGEN). For analysis of associations with RA susceptibility, we used genotyping data from a group of 808 healthy African Americans matched for age and gender, approximately 500 recruited as part of the CLEAR Registry and approximately 300 recruited from the Birmingham area (samples provided by R. Kimberly and J. Edberg, University of Alabama at Birmingham, Birmingham, Alabama, USA). For analysis of associations with radiographic severity, we used genotyping data from RA patients in the CLEAR I cohort who were assigned an SHS at the 3-year visit $(n=139)$. Radiographs of the hands and feet were obtained at baseline and at 3 years, and radiographic damage was quantified using the SHS (31). Clinical data, laboratory data, radiographic data, and CPB2 SNP data were analyzed for female patients only $(n=118)$, because the relatively small number of men who possess the CPB2 SNP rs1926447 minor allele in the CLEAR I cohort $(n=4)$ precluded meaningful analysis.

Effect of $C P B$ variants on $C 5$ a cleavage and activity. Recombinant human Thr325 CPB and Ile325 CPB were expressed in baby hamster kidney cells and purified as described previously (30). Each form of CPB $(0.2 \mu \mathrm{M})$ protein was activated with thrombin $(5 \mathrm{nM})$, thrombomodulin $(20 \mathrm{nM})$, HEPES $(20 \mathrm{mM})$ and $\mathrm{CaCl}_{2}(5 \mathrm{mM})$ in HBSS at $24^{\circ} \mathrm{C}$ for 10 minutes, after which the thrombin was quenched with PPACK $(1 \mu \mathrm{M})$. Recombinant human $\mathrm{C} 5 \mathrm{a}(1 \mu \mathrm{M})$ was then hydrolyzed by each form of activated CPB protein $(2 \mathrm{nM})$ at $37^{\circ} \mathrm{C}$. Aliquots were removed at $0,5,10,20,40$, and $60 \mathrm{~min}-$ utes, and C5a cleavage was stopped by $1 \mathrm{mM}$ EDTA ( $\mathrm{pH}$ 7.6). To evaluate CPB-mediated cleavage of C5a, we measured levels of C5a and C5a-desArg in each reaction mix using an Exactive (Thermo Fisher Scientific) orbitrap mass spectrometer coupled to a UPLC (Waters) chromatograph equipped with a Poroshell 300SB-C3 $75 \times 2 \mathrm{~mm}$ column (Agilent). Detection was performed in $m / z 600-2,000$ mass range using electrospray ionization in positive mode. Spectra of multiply charged ions were deconvoluted using ProMass software (Thermo Fisher Scientific). The C5a-desArg/C5a ratio was calculated for each time point. To evaluate CPB-mediated inhibition of C5a activity, we measured the release of MPO from neutrophils incubated with the CPB-treated C5a. Briefly, neutrophils were prepared, according to a published protocol (58), from buffy-coat concentrates obtained from the Stanford Blood Bank. Neutrophils $\left(4 \times 10^{6}\right.$ cells $\left./ \mathrm{ml}\right)$ were resuspended in HBSS with $0.25 \%$ bovine serum albumin. $1 \mathrm{ml}$ of neutrophils was treated with $5 \mu \mathrm{g} / \mathrm{ml}$ of cytochalasin B for 5 minutes at $37^{\circ} \mathrm{C}$. $1 \mu \mathrm{l}$ of each reaction mix of CPB-cleaved C5a (as described above) was added to the neutrophil suspension, incubated for 15 minutes at $37^{\circ} \mathrm{C}$, and centrifuged. MPO released into the supernatant was measured by a commercial MPO activity assay kit (Invitrogen) at $A_{590}$, as recommended.

Human samples. Human plasma, synovial fluid, and synovial tissue samples were collected from healthy individuals and from RA and OA patients who met American College of Rheumatology criteria. All samples, including samples collected as part of the CLEAR Registry, were obtained and 
used under human subjects protocols approved by the Investigational Review Boards at Stanford University and University of Alabama at Birmingham. All samples were collected after informed consent, except for the synovial fluid samples, which were obtained as discarded remnant tissue under an Investigational Review Board-approved protocol that does not require consent.

ELISA for total CPB, total C5a, and MMP3. A commercial CPB ELISA kit (Zymutest CPB antigen ELISA kit; Aniara) was used for measurement of $\mathrm{CPB}$ protein levels in synovial fluid and plasma. In brief, samples were diluted 1:100. To block nonspecific cross-linking by rheumatoid factor, we preincubated synovial fluid samples with $3 \mu \mathrm{g} / \mathrm{ml}$ of HeteroBlock (Omega Biologicals). $200 \mu \mathrm{l}$ of samples and the standard CPB solution were used to measure total CPB level, according to the manufacturer's instructions. Synovial C5a level was measured with a commercial human C5a ELISA kit (BD Biosciences) according to the manufacturer's instructions. Mouse plasma C5a levels were measured with a commercial mouse C5a ELISA kit (R\&D Systems) according to the manufacturer's instruction. MMP3 levels in FLSs culture supernatants were measured with a commercial MMP3 ELISA kit (R\&D Systems) according to the manufacturer's instructions.

$R A$ FLS culture. RA FLSs were isolated from remnant pannus obtained at knee arthroplasty. Pannus was minced; digested at $37^{\circ} \mathrm{C}$ for 75 minutes with $1 \mathrm{mg} / \mathrm{ml}$ collagenase I (Invitrogen), $0.1 \mathrm{mg} / \mathrm{ml}$ DNase I (SigmaAldrich), and $0.015 \mathrm{mg} / \mathrm{ml}$ hyaluronidase (Sigma-Aldrich); and cultured in DMEM, 10\% FCS, $2 \mathrm{mM}$ L-glutamine, $1 \mathrm{mM}$ sodium pyruvate, $100 \mathrm{U} / \mathrm{ml}$ penicillin, $100 \mu \mathrm{g} / \mathrm{ml}$ streptomycin sulfate, and $50 \mu \mathrm{M} 2$-mercaptoethanol at $37^{\circ} \mathrm{C}, 8 \% \mathrm{CO}_{2}$, as described previously (55). After the fourth passage, RA FLSs were grown to confluence and stimulated with C $5 \mathrm{a}(2.5 \mu \mathrm{g} / \mathrm{ml}$; R\&D Systems) for 24 hours. RNA was isolated for quantitative PCR, and supernatant was collected for ELISA.

Cell isolation and culture. Human promonocytic U937 cells were obtained from the American Type Culture Collection. Buffy coat concentrates were obtained from the Stanford Blood Bank. Neutrophils and mononuclear cells were isolated by centrifugation at $400 \mathrm{~g}$ for 40 minutes with Ficoll-Hypaque. Isolated mononuclear cells $\left(1 \times 10^{9}\right)$ were filtered with a magnetic cell-sorting system (Monocyte Isolation Kit II; Miltenyi Biotec) by negative selection. Retained cells were collected as the nonmonocytic cell population, and filtered cells as the monocytic cell population. For the generation of macrophages, isolated monocytes were cultured with M-CSF (30 ng/ml; Peprotech) in RPMI-1640 containing 10\% FBS for 6 days. Huh-7.5 cells are a human liver hepatoma cell line and were provided by C. Lee, from the laboratory of J. Glenn (Stanford University, Stanford, California, USA).

RT-PCR and quantitative PCR. Total RNA was isolated from cells or synovial tissue using Qiagen RNeasy minikits and reverse transcribed into cDNA by using qScript cDNA synthesis kit (Quanta Bioscience). cDNA was amplified by PCR using Top DNA polymerase with universal PCR premix (Bioneer). Primer sequences for standard PCR amplification were as follows: CPB2 forward, 5'-CCATGCCAGAGAATGGATCT-3'; CPB2 reverse, 5'-ATTCAGGTCTGTTCCGATGC-3'; ACTB forward, 5'-CCAACCGCGAGAAGATGA-3'; ACTB reverse, 5'-TAGCACAGCCTGGATAGCAA-3'. Liver cDNA (Clontech) was used as a positive control. Quantitative PCR was performed using SYBR Green PCR Kits with the Taqman system (Thermo Fisher Scientific), and mRNA levels were normalized according to levels of the housekeeping gene hypoxanthine-guanine phosphoribosyl transferase (HPRT). Primer sequences for quantitative PCR analysis were as follows: HPRT forward, 5'-CAGGCAGTATAATCCAAAGAT-3'; HPRT reverse, $5^{\prime}$-TCTGGCTTATATCCAACACTTC-3'; CPB2 forward, 5'-GCCGTGTGTGTACCTG-3'; CPB2 reverse, 5'-AAAGGTGCGTCAAGTT-3'; MMP1 forward, 5'-TTCGGGGAGAAGTGATGTTC-3'; MMP1 reverse, 5'-TTGTG-
GCCAGAAAACAGAAA-3'; MMP3 forward, 5'-AGTCTTCCAATCCTACTGTTG-3'; MMP3 reverse, 5'-TCCCCGTCACCTCCAATCC-3'; MMP13 forward, 5'-ACTGAGAGGCTCCGAGAAATG-3'; MMP13 reverse, 5'-TGTTATCGTCAAGTTTGCCAG-3'.

Western blotting. After stimulation with dexamethasone (American Regent), U937 or Huh-7.5 cells were lysed with cell lysis buffer (Mammalian Protein Extraction Reagent; Pierce) containing a protease and phosphatase inhibitor cocktail (Fisher Scientific). Protein lysates were separated by SDS-PAGE, and Western blotting was performed using mouse monoclonal anti-CPB antibody (Haematologic Technologies) or mouse monoclonal anti- $\beta$-actin antibody (Sigma-Aldrich).

Immunobistochemistry. Paraffin-embedded RA synovial tissue sections were prepared through a series of xylene and alcohol rinses and hydration with $\mathrm{H}_{2} \mathrm{O}$. Endogenous peroxidase activity was quenched with $3 \% \mathrm{H}_{2} \mathrm{O}_{2}$ solution (EMD Chemicals), and nonspecific binding blocked with serumfree protein block (Dako). The tissue sections were incubated with rabbit polyclonal anti-CBP antibody (Sigma-Aldrich) or normal rabbit IgG (Santa Cruz) and labeled with Envision+ Rabbit-HRP polymer (Dako). Staining was developed with $\mathrm{DAB}+$ substrate-chromogen solution (Dako), and counterstaining was performed with hematoxylin (Dako).

Statistics. Statistical data are presented as mean \pm SEM unless otherwise indicated. Statistical differences were assessed by 2-tailed Student's $t$ test for ELISA data and by Mann-Whitney $U$ test for in vivo experiments. For evaluation of the effect of CPB2 SNPs on disease susceptibility or severity, $\chi^{2}$ test was used. For assessment of the correlation between synovial CPB level and C5a level, Pearson correlation test was used.

When multiple comparisons were sought, 1-way ANOVA with appropriate post-hoc tests was used. In all analyses, $P$ values less than 0.05 were considered significant. Statistical analyses were performed using SPSS for Windows, version 16.0 (SPSS), or GraphPad Prism, version 5.1 (GraphPad).

\section{Acknowledgments}

This work was supported by Department of Veterans Affairs funding, NIH NIAID grant R01-AI085268, NHLBI grant N01-HV00242 Proteomics Center, and ACR Within-Our-Reach funding to W.H. Robinson; NIH NHLBI grant R01-HL057530 to L.L. Leung; ACR physician scientist development award, ACR/AF bridge funding award, and NIH NIAMS grant K08-AR056772 to J.J. Song; grants from the Heart and Stroke Foundation of Ontario to M. Nesheim; and NIH NHLBI grant N01-AR62278, NIH NIAMS grant P60AR048095, and NIH NCRR grant UL1-RR025777 to S.L. Bridges, Jr. We thank members of the Robinson and Leung laboratories for insightful discussions and technical support; Robert P. Kimberly and Jeffrey C. Edberg for providing approximately 300 African American controls for genotyping; and V. Michael Holers for provision of the anti-C5 antibody BB5.1. We thank CLEAR Registry Investigators Larry W. Moreland (University of Pittsburgh), George Howard (University of Alabama at Birmingham), Doyt L. Conn (Emory University), Beth L. Jonas (University of North Carolina), Leigh F. Callahan (University of North Carolina), Edwin A. Smith (Medical University of South Carolina), and Richard D. Brasington, Jr. (Washington University).

Received for publication January 12, 2011, and accepted in revised form June 1, 2011.

Address correspondence to: William H. Robinson, Division of Rheumatology Department of Medicine, Stanford University, 3801 Miranda Ave, MC 154R, Palo Alto, California 94304, USA. Phone: 650.849.1207; Fax: 650.849.1208; E-mail: wrobins@stanford.edu. 
1. Busso N, Hamilton JA. Extravascular coagulation and the plasminogen activator/plasmin system in rheumatoid arthritis. Arthritis Rheum. 2002; 46(9):2268-2279.

2. Barnhart MI, Riddle JM, Bluhm GB, Quintana C. Fibrin promotion and lysis in arthritic joints. Ann Rheum Dis. 1967;26(3):206-218.

3. Weinberg JB, Pippen AM, Greenberg CS. Extravascular fibrin formation and dissolution in synovial tissue of patients with osteoarthritis and rheumatoid arthritis. Arthritis Rheum. 1991;34(8):996-1005

4. Flick MJ, et al. Fibrin(ogen) exacerbates inflammatory joint disease through a mechanism linked to the integrin alphaMbeta 2 binding motif. J Clin Invest. 2007;117(11):3224-3235.

5. Masson-Bessiere C, et al. The major synovial targets of the rheumatoid arthritis-specific antifilaggrin autoantibodies are deiminated forms of the alpha- and betachains of fibrin. J Immunol. 2001;166(6):4177-4184.

6. Marty I, Peclat V, Kirdaite G, Salvi R, So A, Busso N. Amelioration of collagen-induced arthritis by thrombin inhibition. J Clin Invest. 2001;107(5):631-640.

7. Solomon DH, et al. Cardiovascular morbidity and mortality in women diagnosed with rheumatoid arthritis. Circulation. 2003;107(9):1303-1307.

8. Choi HK, Hernan MA, Seeger JD, Robins JM, Wolfe F. Methotrexate and mortality in patients with rheumatoid arthritis: a prospective study. Lancet. 2002. 359(9313):1173-1177.

9. Bajzar L, Manuel R, Nesheim ME. Purification and characterization of TAFI, a thrombin-activable fibrinolysis inhibitor. J Biol Chem. 1995; 270(24):14477-14484.

10. Mosnier LO, Buijtenhuijs P, Marx PF, Meijers JC, Bouma BN. Identification of thrombin activatable fibrinolysis inhibitor (TAFI) in human platelets. Blood. 2003;101(12):4844-4846.

11. Redlitz A, Nicolini FA, Malycky JL, Topol EJ, Plow EF. Inducible carboxypeptidase activity. A role in clot lysis in vivo. Circulation. 1996;93(7):1328-1330.

12. Bajzar L, Morser J, Nesheim M. TAFI, or plasma procarboxypeptidase $\mathrm{B}$, couples the coagulation and fibrinolytic cascades through the thrombinthrombomodulin complex. J Biol Chem. 1996; 271(28):16603-16608.

13. Redlitz A, Tan AK, Eaton DL, Plow EF. Plasma carboxypeptidases as regulators of the plasminogen system. J Clin Invest. 1995;96(5):2534-2538.

14. Myles T, et al. Thrombin activatable fibrinolysis inhibitor, a potential regulator of vascular inflammation. J Biol Chem. 2003;278(51):51059-51067.

15. Sharif SA, et al. Thrombin-activatable carboxypeptidase $B$ cleavage of osteopontin regulates neutrophi survival and synoviocyte binding in rheumatoid arthritis. Arthritis Rheum. 2009;60(10):2902-2912.

16. Bruno NE, et al. Protective role of thrombin activatable fibrinolysis inhibitor in obstructive nephropathy-associated tubulointerstitial fibrosis. J Thromb Haemost. 2008;6(1):139-146.

17. Asai S, et al. Procarboxypeptidase R deficiency causes increased lethality in concanavalin A-induced hepatitis in female mice. Biol Pharm Bull. 2010; 33(7):1256-1259

18. Hall JM. Bradykinin receptors: pharmacological properties and biological roles. Pharmacol Ther. 1992; 56(2):131-190.

19. Tanaka D, Kagari T, Doi H, Shimozato T. Essential role of neutrophils in anti-type II collagen antibody and lipopolysaccharide-induced arthritis. Immunology. 2006;119(2):195-202

20. Morser J, Gabazza EC, Myles T, Leung LL. What has been learnt from the thrombin-activatable fibrinolysis inhibitor-deficient mouse? J Thromb Haemost.
2010;8(5):868-876

21. Nagase H, Enghild JJ, Suzuki K, Salvesen G. Stepwise activation mechanisms of the precursor of matrix metalloproteinase 3 (stromelysin) by proteinases and (4-aminophenyl)mercuric acetate. Biochemistry. 1990;29(24):5783-5789.

22. Busso N, et al. Exacerbation of antigen-induced arthritis in urokinase-deficient mice. J Clin Invest. 1998;102(1):41-50.

23. Banda NK, et al. Mechanisms of effects of complement inhibition in murine collagen-induced arthritis. Arthritis Rheum. 2002;46(11):3065-3075

24. Nandakumar KS, Svensson L, Holmdahl R. Collagen type II-specific monoclonal antibody-induced arthritis in mice: description of the disease and the influence of age, sex, and genes. Am J Pathol. 2003; 163(5):1827-1837.

25. Ooi YM, Colten HR. Genetic defect in secretion of complement C5 in mice. Nature. 1979; 282(5735):207-208.

26. Nishimura T, Myles T, Piliponsky AM, Kao PN, Berry GJ, Leung LL. Thrombin-activatable procarboxypeptidase B regulates activated complement C5a in vivo. Blood. 2007;109(5):1992-1997.

27. Mullaly SC, Kubes P. Mast cell-expressed complement receptor, not TLR2, is the main detector of zymosan in peritonitis. Eur Immunol. 2007;37(1):224-234

28. Brouwers GJ, et al. A novel, possibly functional, single nucleotide polymorphism in the coding region of the thrombin-activatable fibrinolysis inhibitor (TAFI) gene is also associated with TAFI levels. Blood. 2001;98(6):1992-1993.

29. Zhao L, Morser J, Bajzar L, Nesheim M, Nagashima M. Identification and characterization of two thrombin-activatable fibrinolysis inhibitor isoforms. Thromb Haemost. 1998;80(6):949-955.

30. Schneider M, Boffa M, Stewart R, Rahman M, Koschinsky M, Nesheim $M$. Two naturally occurring variants of TAFI (Thr-325 and Ile-325) differ substantially with respect to thermal stability and antifibrinolytic activity of the enzyme.J Biol Chem. 2002; 277(2):1021-1030

31. van der Heijde D. How to read radiographs according to the Sharp/van der Heijde method. J Rheumatol. 1999;26(3):743-745.

32. Smolen JS, et al. Predictors of joint damage in patients with early rheumatoid arthritis treated with high-dose methotrexate with or without concomitant infliximab: results from the ASPIRE trial. Arthritis Rheum. 2006;54(3):702-710.

33. So AK, et al. Arthritis is linked to local and systemic activation of coagulation and fibrinolysis pathways. J Thromb Haemost. 2003;1(12):2510-2515.

34. Guo X, et al. Arginine carboxypeptidase (CPR) in human plasma determined with sandwich ELISA. Microbiol Immunol. 1999;43(7):691-698.

35. Peters MJ, Nurmohamed MT, van Eijk IC, Verkleij CJ, Marx PF. Thrombin-activatable fibrinolysis inhibitor and its relation with inflammation in rheumatoid arthritis. Ann Rheum Dis. 2009;68(7):1232-1233.

36. Paniagua RT, et al. c-Fms-mediated differentiation and priming of monocyte lineage cells play a central role in autoimmune arthritis. Arthritis Res Ther. 2010;12(1):R32.

37. Esmon CT. The interactions between inflammation and coagulation. BrJ Haematol. 2005;131(4):417-430.

38. Szaba FM, Smiley ST. Roles for thrombin and fibrin(ogen) in cytokine/chemokine production and macrophage adhesion in vivo. Blood. 2002; 99(3):1053-1059

39. Sarangi PP, Lee HW, Kim M. Activated protein Caction in inflammation. BrJ Haematol. 2010;148(6):817-833. 40. McCachren SS, Diggs J, Weinberg JB, Dittman WA.
Thrombomodulin expression by human blood monocytes and by human synovial tissue lining macrophages. Blood. 1991;78(12):3128-3132.

41. Esmon CT. Molecular events that control the protein C anticoagulant pathway. Thromb Haemost. 1993; 70(1):29-35.

42. Ji H, et al. Arthritis critically dependent on innate immune system players. Immunity. 2002; 16(2):157-168

43. Okroj M, Heinegard D, Holmdahl R, Blom AM. Rheumatoid arthritis and the complement system. Ann Med. 2007;39(7):517-530.

44. Kozian DH, Lorenz M, Marz W, Cousin E, Mace S, Deleuze JF. Association between the Thr325Ile polymorphism of the thrombin-activatable fibrinolysis inhibitor and stroke in the Ludwigshafen Risk and Cardiovascular Health Study. Thromb Haemost. 2010; 103(5):976-983.

45. Heylen E, et al. Procarboxypeptidase U (TAFI) contributes to the risk of thrombosis in patients with hereditary thrombophilia. Thromb Res. 2009; 124(4):427-432

46. de Bruijne EL, et al. Genetic variation in thrombinactivatable fibrinolysis inhibitor (TAFI) is associated with the risk of splanchnic vein thrombosis. Thromb Haemost. 2007;97(2):181-185.

47. de Bruijne EL, et al. The role of thrombin activatable fibrinolysis inhibitor in arterial thrombosis at a young age: the ATTAC study. J Thromb Haemost. 2009;7(6):919-927.

48. Tu Z, Bu H, Dennis JE, Lin F. Efficient osteoclast differentiation requires local complement activation. Blood. 2010;116(22):4456-4463.

49. Gregersen PK. Susceptibility genes for rheumatoid arthritis - a rapidly expanding harvest. Bull NYU Hosp Jt Dis. 2010;68(3):179-182.

50. Burch F, Tesser J, Bell L, Kivitz A. Baseline C5b9 level correlates with CRP and ACR 20 response to the humanized anti-C5 antibody h5G1.1 in patients with rheumatoid arthritis. Arthritis Rheum. 2001; 44(suppl 9):S214.

51. Vergunst CE, et al. Blocking the receptor for C5a in patients with rheumatoid arthritis does not reduce synovial inflammation. Rheumatology (Oxford). 2007; 46(12):1773-1778.

52. Boffa MB, Bell R, Stevens WK, Nesheim ME. Roles of thermal instability and proteolytic cleavage in regulation of activated thrombin-activable fibrinolysis inhibitor. J Biol Chem. 2000;275(17):12868-12878.

53. Marx PF, et al. Crystal structures of TAFI elucidate the inactivation mechanism of activated TAFI: a novel mechanism for enzyme autoregulation. Blood. 2008;112(7):2803-2809.

54. Schultz G, et al. Enhanced abdominal aortic aneurysm formation in thrombin-activatable procarboxypeptidase B-deficient mice. Arterioscler Thromb Vasc Biol. 2010;30(7):1363-1370.

55. Paniagua RT, et al. Selective tyrosine kinase inhibition by imatinib mesylate for the treatment of autoimmune arthritis. JClin Invest. 2006;116(10):2633-2642.

56. Kolaczkowska E, Seljelid R, Plytycz B. Role of mast cells in zymosan-induced peritoneal inflammation in Balb/c and mast cell-deficient WBB6F1 mice. J Leukoc Biol. 2001;69(1):33-42.

57. Bridges SL Jr, et al. Radiographic severity of rheumatoid arthritis in African Americans: results from a multicenter observational study. Arthritis Care Res (Hoboken). 2010;62(5):624-631.

58. Henson PM, Zanolari B, Schwartzman NA, Hong SR Intracellular control of human neutrophil secretion. I. C5a-induced stimulus-specific desensitization and the effects of cytochalasin B. J Immunol. 1978; 121(3):851-855 